\title{
The Application and Effect Analysis of Colour in New Media Advertisement
}

\author{
Xiaodan Li \\ Shenyang University
}

\begin{abstract}
Keywords: Advertising color; Color association; New media advertisement; Age of picture-reading; Vision induction
\end{abstract}

\begin{abstract}
Nowadays, color occupies an important status in advertisement. Under fast food reading mode and the age of picture-reading, the special effect of color on new media advertisementcannot be neglected. It can directly affect target audience's psychology and even consumer behavior to varying degrees. This paper detailedly elaborates on color's effects on target audience as well as its particularity under propagation mode of new media advertisement, and especially analyzes the color's impact on consumer psychology in new media advertisement.
\end{abstract}

\section{The Impact of Color on Target Audience}

Definition of Color. Color is the visual effect of light reflected by the eyes, the brain, and our life experience. In the process of the development of human material life and spiritual life, color always sparks magical charm.

The Cognition of Color (Human Beings). Human beings not only discover, observe, create and appreciate the colorful world, but also deepen the understanding and application of color through the change of the times. No matter the understanding of color or its utilization process, it is a development from the perceptual sublimation to rational process for human beings. The so-called rational color, which uses the unique ability of abstract thinking, such as judgment, reasoning, deduction and so on, regularly reveals the complex and complicated color impressions through direct sense from nature, with the result that it forms the theory and law of color and is applied to the practice. Human's perception of color is not only determined by the physical properties of light, for example, it's often affected by the surrounding color as well. Sometimes, people also refer to the physical properties that substance generates different colors as colors. Generally speaking, human's perception of color is the most direct and strongest.

Color Association. Color association is affected by the age, gender, personality, culture, education, occupation, nationality, religion, living environment, background, life experience and so on. Color association is divided into concrete association and abstract association. Figurative association refers that when people see a certain color, they will associate with some specific things in nature and life. For examples, people can associatewith blood when seeing red, red flag, sunrise and so on, and people can also associate with concrete things when seeing green such as grass, green space and so on. Generally, in our opinion, yellow often refers to vitality, sunshine, wheat, hope, skin, noble and luxurious; Green refers to life, fresh, plant, oxygen and lively; Blue refers to sky, pure, deep, beautiful, wide and melancholy;Purple refers to charm, sadness and high - profile; Black refers to dark, silent, lonely, fear, helplessness, death and sexy; Grey refers to dead, dust and cold; White refers to pure, transparent, marriage, death, confusion and clean. However, abstract association refers that people will associate to the sense, noble and other abstract concepts when seeing a certain color, and then may associate with pure, simple, elegant and other abstract things when they see white.

Advertising color. Advertising color is the most sensitive factor in advertising performance and it is also one of the elements of advertising performance. As a result, more and more people pay attention to it. All life necessities as well as other consumer goods have their own colors. Meanwhile, advertising color is also the second language of advertising which plays an important role in advertising design, and its function is to deliver commodity information to the audience. 
That's why advertising color is closely related to audience's psychological reaction, likewise, advertising color can make an important effect on audience psychology.

As a visual language, advertising color conveys advertising content together with graphics and text. Human's visible sensation has a strong discrimination ability for advertising color, and it can

identify millions of colors, so advertising color has rich expressive force. When watching advertising, associations of life affairs often generated in mind due to the visual stimulation of color. Different colors represent different feelings, and have different symbolic meanings. Phenomenon that audience often produce different psychological feelings is mainly related to the expression effect of advertising color.

\section{The Particularity of New Media Propagation Mode}

New Media and the Era of Picture-Reading. With the development of science and technology and the acceleration of pace of life, new media has came into being, meanwhile, modern people have entered this era: We found that text reading is boring and unfulfilling. People need some pictures to stimulate their eyes andtheir thirst for knowledge and even to excite their numb nerves. Speaking of articles on the reading picture age: I have seen someone's opinion when reading "the era of reading pictures": Now we have entered the era of "picture-reading", various kinds of pictures are generally presented in front of people, and reading pictures has become a fashion nowadays. In my opinion, it is a performance of scientific and technological progress for entering the era of "reading picture". The development of printing industry, the popularity of cultural education, the increasing number of print media such as newspapers and magazines as well as appearance of more and more colorful pictures, movies, television programs, videos, and images in the network and so on, all these are unthinkable in the past backward period.However, in such an era, color plays a vital role. For example, color has a prior advantage in visual impact when the audience appreciates pictures. Therefore, we must pay attention to the visual, emotional, and functional features of advertising color in the new media advertising, and fully understand the sensory experiences brought to consumers from different colors.

New Media and Fine Arts. New media focuses on art of science and technology. What's its main feature-it's to apply advanced technology to the works of art. However, with the development of the times, the application field of new media has become more extensive, therefore, the content and meaning of the interactive communication of the new media become richer, the scope of interactive communication becomes broader, and many other factors also have impacts on it. Color, as an important element in the interactive communication of new media, has certain theoretical and practical significance. At present, interactive communication of new media has become a beautiful landscape in current media communication, and it is not only a hot topic of the discussion in the painting field, but also the focus of varied walks of life. Therefore, we can say that it's a better development significance for the study of the application of color in interactive communication of new media.

\section{Color Application and Audience's Psychology of New Media Advertising}

With the development of information technology, new media advertising plays an increasingly important role in marketing, to a large extent, advertising may lead, change or even mislead consumers to consume. However, in the composition of advertising, color is one of the most important factors, because the stimulation of different colors towards consumers is completely different. They may convey different information to consumers. Advertising color has an unusual significance to the commodity. They give consumers a strong appeal and intimacy through the combination of different colors.

Regardless of the cultural customs, people have some accordant understanding of color in most countries of the world. In this paper, we mainly research on the relationship between red, orange, yellow, blue, green and purple and consumers, and explore the tone conveyed by these colors.

Many people love red, because red represents passion, and gives people hope and vitality. In 
China's traditional culture, red is always the representation of auspice. Every year after the spring festival, especially in ancient times, Chinese people like to decorate their house with red things, and we also dress ourselves a set of red clothes. In addition, red also has a meaning of warding off evil spirits. But red represents impulsion and tension in some ways, so in some shopping software, new media ads will be inserted red elements. Yellow particularly represents vivid, and gives people a feeling of purity. People favor it because of their special crisp feeling. However, yellow sometimes is associated with weak, disease, or even sudden emptiness and so on. So some new media platforms related to health often avoid using yellow tone as much as possible in typography. Orange always gives people a feeling of warm. It becomes popular in many countries. Orange neutralizes red and yellow characteristics, it is an color full of excessive emotion, and it is lukewarm and loved by everyone. For this reason, many new media platforms like to decorate with orange.

Blue is an extreme cold color, with quiet and rational characteristics, and it is opposed to red. Blue can easily give people a clear, detached, and unworldly feeling. However, many masters who are eccentric and accomplished are obsessed with blue, which makes people associate blue with gloom and mystery. As a result, many new media ads often use blue as the background color of some high-end technology products, while some shopping season frenzy will not use blue tone, such as 12th, December in China. Green is a color standing for spring, which always represents life, youth, and unlimited vitality. But sometimes, greenalso indicates immature behavior. Dark green is easy to produce a feeling of negative and cold. Purple always gives people a feeling of noble, with elegance and decency, grace and luxury. It combines the personality of red and the characteristics of blue. Dark purple can cause deep, depressed, mysterious feelings. These colors will also be considered in the specific operation of new media advertising, be appropriately used to bring the psychological and emotional response, and operate more beneficial service.

Facts have proved that color has been more and more attentive and favored by large companies and enterprises in examples of real new media advertising. Some special color and color combinations are boldly used in advertising to carry out product or enterprise propaganda, in order to achieve their desired symbolic role and effect.

\section{References}

[1] A.Q.Song: Research on new media advertising communication[D], Harbin Normal University, 2016.(In Chinese)

[2] H.Zhang: The Research of Color Visual Effect in Commodity Advertisement Design[J], Popular Culture and Arts Publishing House, 2015(01).(In Chinese)

[3] Y.Liu and L.Li: Discussion on the Color Utilization Art in Commercial Media Advertisement Design[J], China Newspaper Industry, 2011(04).(In Chinese)

[4] H.Zhang: The Research of Color Visual Effect in Commodity Advertisement Design[J], Popular Culture and Arts Publishing House, 2015,(01):96-97.(In Chinese)

[5] Y.F.Peng: Interpret the Images Era, China Social Sciences Press,2011.1.1.(In Chinese)

[6] Y.X.Bao: A Study of Visual Culture in Industrial Design[D], East China Normal University, 2013.(In Chinese)

[7] S.C.Wang: Discussion on the Application of Color Meaning in Advertising Language[J], Journal of Shandong Administrative College and Shandong Economic Management Personnel College, 2009(05).(In Chinese) 